\title{
Article \\ Evaluation of the Strength Characteristics of Silty-Clayey Soils during Freezing-Thawing Cycles
}

\author{
Elena Bragar ${ }^{1,2, *(\mathbb{D})}$, Yakov Pronozin ${ }^{2}$, Askar Zhussupbekov ${ }^{1,3,4}$, Alexander Gerber ${ }^{5}$, Assel Sarsembayeva ${ }^{1}(\mathbb{D}$, \\ Tymarkul Muzdybayeva ${ }^{6}(1)$ and Ulbossyn Zhangabilkyzy Sarabekova ${ }^{7}$
}

1 Department of Civil Engineering, L.N. Gumilyov Eurasian National University, Nur-Sultan 010008, Kazakhstan; astana-geostroi@mail.ru (A.Z.); assel_enu@mail.ru (A.S.)

2 Department of Construction Operations, Industrial University of Tyumen, 625000 Tyumen, Russia; geofond.tgasu@gmail.com

3 Department of Geotechnics, Saint Petersburg State University of Architecture and Civil Engineering (SPbGASU), 190005 Saint Petersburg, Russia

4 Department of Soil Mechanics and Geotechnics, Moscow State University of Civil Engineering (MGSU), 129337 Moscow, Russia

5 A.I. Proshlyakov Tyumen Higher Military Engineering Command College, 625001 Tyumen, Russia; gerber_a@mail.ru

6 Department of Architecture and Design, S.Seifullin Kazakh Agro Technical University, Nur-Sultan 010011, Kazakhstan; tumar2304@mail.ru

7 Department of Electricity and Life Safety, Korkyt Ata Kyzylorda University, Kyzylorda 120014, Kazakhstan; ulbolsyn.sar@mail.ru

* Correspondence: el.bragar@yandex.ru; Tel.: +7-9324750527

check for updates

Citation: Bragar, E.; Pronozin, Y.; Zhussupbekov, A.; Gerber, A.; Sarsembayeva, A.; Muzdybayeva, T.; Sarabekova, U.Z. Evaluation of the Strength Characteristics of Silty-Clayey Soils during Freezing-Thawing Cycles. Appl. Sci. 2022, 12, 802. https://doi.org/ 10.3390/app12020802

Academic Editor: Daniel Dias

Received: 7 December 2021

Accepted: 9 January 2022

Published: 13 January 2022

Publisher's Note: MDPI stays neutral with regard to jurisdictional claims in published maps and institutional affiliations.

Copyright: (C) 2022 by the authors. Licensee MDPI, Basel, Switzerland. This article is an open access article distributed under the terms and conditions of the Creative Commons Attribution (CC BY) license (https:// creativecommons.org/licenses/by/ $4.0 /)$.

\begin{abstract}
Destructuring settlements due to frost heave during the structures' exploitation are often not taken into account at the designing stage, although they are indirectly related to the bearing capacity of the soils. The objective of this research was analyzing the effect of the number of freezingthawing cycles on the strength characteristics of soils. A paired experiment with various initial parameters (void ratio, initial moisture content, and the number of freezing-thawing cycles) was carried out. According to the experimental results, the cohesion largely depends on the above parameters which might lead to its decrease by up to three times. The angle of internal friction demonstrated an indefinite behavior during the freeze-thaw cycles, which is confirmed by a literature review. Freezing-thawing cycles significantly decrease the soil bearing capacity: up to $44 \%$ after 10 freezing-thawing cycles for soil with $e=0.55$ and $w=16.5 \%$. However, in the case of $e=0.75$ and $w=22.6 \%$, it increased by $33 \%$. A program based on the least-squares method was used to calculate the approximation coefficients of the dependence describing the changes in strength characteristics from the abovementioned parameters. Changes in strength characteristics must be taken into account when designing structures, as they can lead to additional settlement or even subsidence of the foundations.
\end{abstract}

Keywords: silty-clayey soil; freezing-thawing cycles; angle of internal friction; cohesion; void ratio; soil moisture content

\section{Introduction}

Many scientists around the world have observed changes in soil moisture and density during freeze-thaw cycles and, accordingly, a change in bearing capacity, directly related to engineering characteristics [1-3]. Options for addressing these impacts were investigated by [4-6]. Russian scientists from the Soviet era, including M.N. Goldstein, A.M. Pchelintsev, E.P. Shusherina, and N.A. Tsytovich [7-11], have studied the influence of the number of freezing-thawing cycles on the mechanical properties of soils and contributed to the development of methods for strengthening base soils subject to freezing [12,13]. 
A significant part of the conducted experiment deals with road construction in areas with seasonally frozen soils, as well as problems associated with freezing-thawing of the roadway and its subgrade, such as settlement, frost heaving, and slope sliding (Ling et al., 2009; Li et al., 2016; Tebaldi et al., 2016) [14-16].

Destructuring settlement and heave settlement during the exploitation of buildings and structures are not taken into account in most construction design standards, although they are indirectly related to the strength characteristics of the soil. According to [17], the vertical deformation of foundations on a natural base is determined as the sum of four components Equation (A1) (Appendix A): calculated settlement, elastic settlement, destructuring settlement, and heave settlement.

Destructuring settlement $S_{\text {destr }}$ and heave settlement $S_{\text {heave }}$ are not taken into account by domestic standards [18] and are indirectly related to the strength characteristics of soil. The change to these characteristics caused by freezing-thawing is studied in this paper.

Many geotechnical scientists have paid great attention to studying the changes caused by freezing in the cohesion and the angle of internal friction of the soil as these are the main strength characteristics. It is generally accepted that with an increase in the number of freezing-thawing cycles, cohesion decreases, but the stabilized value of cohesion after several freezing-thawing cycles remains controversial [19-24]. However, some results show that cohesion increases or defies the obvious law when exposed to freezing-thawing [25]. Studies of changes in the angle of internal friction of soil are rather contradictory: according to some studies $[1,21,22,25]$, the angle of internal friction increases; according to other studies [19], it decreases or remains constant [24,26,27]. Some studies note the inconsistent nature of the change in the angle of internal friction during freezing-thawing $[20,23,28]$. One way or another, the obtained scientific results are difficult to apply in engineering practice unambiguously. In 2018, Wang et al. were the first to propose a mathematical equation using correction factors for calculating the shear strength of soil during freezingthawing, which had never been considered before [21]. However, the dependence is only for clays with a moisture content of $18.5 \%$.

The purpose of this research is to analyze and to study the mathematical dependence of changes in the strength characteristics of clayey soils with different void ratios and initial moisture content due to freezing-thawing cycles.

\section{Materials and Methods}

The southern area of the Tyumen region of the Russian Federation contains siltyclayey soils which are considered as frost-susceptible soils, resulting in severe frost heave during the winter time. Remolded clay loam samples with the particle density $2.70 \mathrm{~g} / \mathrm{cm}^{3}$ were compacted in accordance with the Russian State Standard GOST 30416-2012 "Soils. Laboratory testing. General" [29]. The samples were compacted in three layers, with the required density and moisture content. The specimens were prepared as cylinders in metal rings of $71.5 \mathrm{~mm}$ in diameter and $35 \mathrm{~mm}$ in height. Physical characteristics of the soils are presented in Table 1.

Table 1. Physical characteristics of the soil.

\begin{tabular}{ccccc}
\hline No. & Designation & Indicator & Unit & Value \\
\hline 1 & $\rho_{S}$ & Density of soil particles & $\mathrm{g} / \mathrm{cm}^{3}$ & 2.70 \\
2 & $w_{P}$ & Plastic limit & - & 0.15 \\
3 & $w_{L}$ & Liquid limit & - & 0.27 \\
4 & $I_{P}$ & Plasticity index & - & 12.1 \\
5 & $I_{L}$ & Liquidity index & - & 0.375 \\
\hline
\end{tabular}

In the experiment, four paired samples were considered for testing with varied initial settings (Table 1). However, only one sample of the pair was subjected to 10 freeze-thaw cycles and the second remained in its original state. 
As part of the study, a two-level analysis was carried out based on three parameters. Each experimental set was formed from a pair made up of a soil sample subjected to the freeze-thaw cycles, and one that remained unaffected (Figure 1). The three variable parameters in the sample preparation are introduced below:

1. Soil void ratio: low level at 0.55 unit fractions (" - " level) and high level at 0.75 unit fractions ("+" level);

2. Initial soil moisture content: conventionally designated as low level at $22.6 \%$ (" -" level) and high level at $19.5 \%$ ("+" level), which corresponds to the high-plastic and semi-solid consistency of soil;

3. Number of freezing-thawing cycles: low level at 0 cycles (" - " level) and high level at 10 cycles ("+" level).

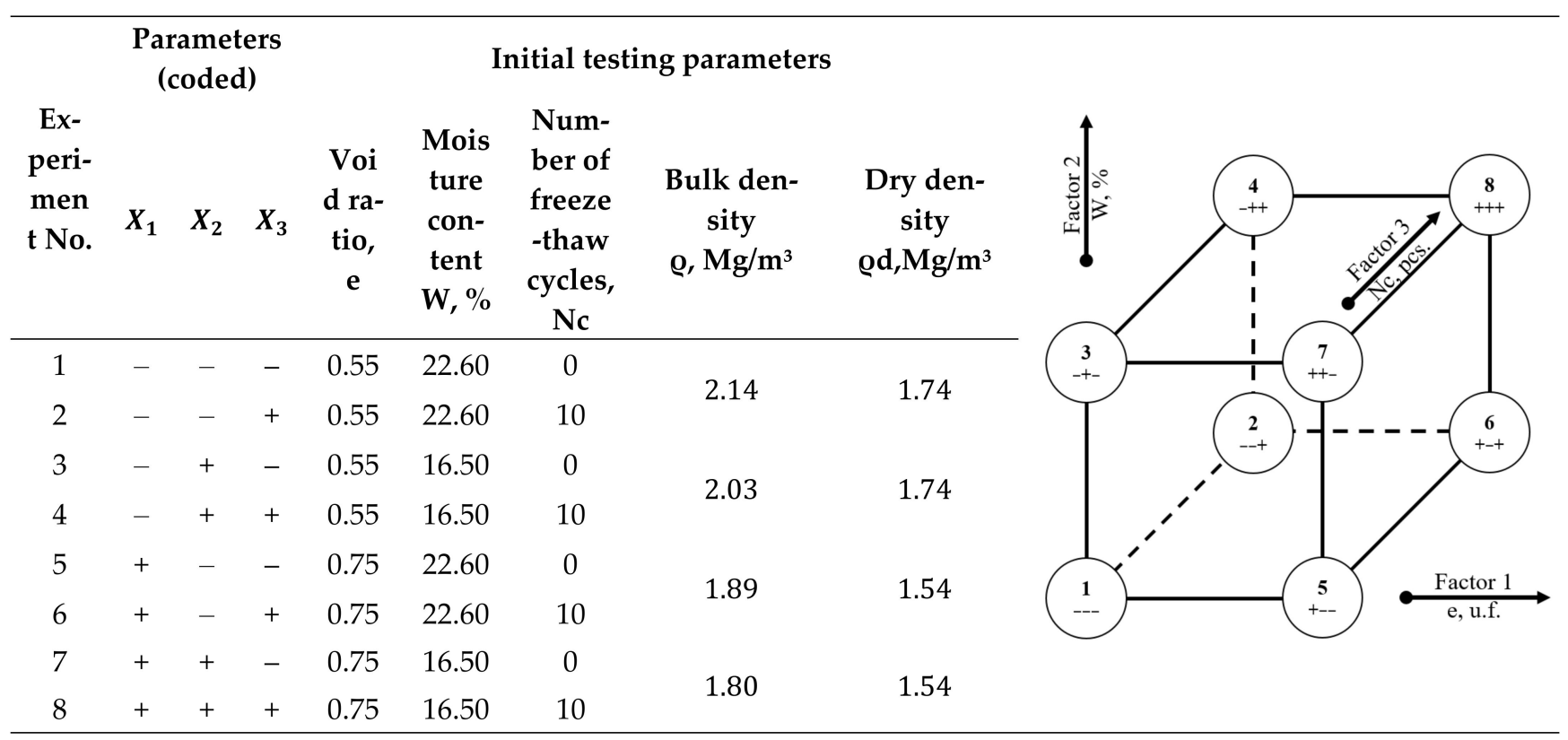

Figure 1. Graphical representation of the experiment matrix.

The experiment set matrix is presented in Table 2.

Table 2. Direct shear test results.

\begin{tabular}{ccc}
\hline Sample No. & Angle of Internal Friction $\boldsymbol{\varphi}^{\boldsymbol{}^{\circ}}$ & Cohesion $\mathbf{c}, \mathbf{k P a}$ \\
\hline 1 & 8 & 36 \\
2 & 12 & 24 \\
3 & 12 & 39 \\
4 & 13 & 28 \\
5 & 12 & 13 \\
6 & 18 & 3 \\
7 & 12 & 26 \\
8 & 13 & 25 \\
\hline
\end{tabular}

According to Russian Standard GOST 25100-2020 "Soils. Classification" [30] the degree of saturation in soil samples \#1-2 is classified as fully saturated $(S r \approx 1.00)$, samples \#3-6 as semi-saturated $(S r=0.81)$, and samples \#7-8 as slightly wet $(S r=0.59)$.

The samples were frozen at a temperature of $-20^{\circ} \mathrm{C}$ and thawed at $20^{\circ} \mathrm{C}$, with the freezing time and thawing time each being $12 \mathrm{~h}$. The specimens were covered with sleeves during the freeze-thaw cycling to prevent the evaporation of water. The all-round freezing method with constant temperature was applied for the freeze-thaw cycle test in a closed system without a water supply. The samples were placed in metal rings without normal stress. 
The engineering properties of soil samples after freeze-thaw cycles were determined using a direct shear apparatus, according to GOST 12248-2010 "Soils. Laboratory methods for determining the strength and strain characteristics" [31]. Four shear tests were conducted with normal stresses 100, 150, 200, and $300 \mathrm{kPa}$. After conducting experiments under each set of conditions and processing the results of the direct shear test, the data were analyzed to determine the influence of each of the studied factors [32].

The assessment of the effect of each parameter $\left(X_{1}, X_{2}\right.$, and $\left.X_{3}\right)$ for the designed three-parameter two-level experiment is presented in Figure 2. In this case, we have four pairwise comparisons for each parameter that give the effect grade values. As an example, the main effect of the parameter $\boldsymbol{X}_{\mathbf{1}}$ is considered, which is calculated as the average of these four comparisons. The effect of $X_{1}$ is regarded as the average of the four $Y_{\mathrm{s}}$ at the high level of $X_{1}$ minus the average of the four $Y_{S}$ at the low level of $X_{1}$. The results of the eight experiments carried out were used to calculate the $X_{2}$ and $X_{3}$ effects in a similar way (by subtracting the average $Y$ value at the low parameter level from the average $Y$ value at the high parameter level). Here, $Y$ parameters are the results of the direct shear test in terms of angle of internal friction and cohesion.

\begin{tabular}{|c|c|c|c|c|}
\hline No. & $X_{1}$ & $X_{2}$ & $X_{3}$ & $Y$ \\
\hline 1 & - & - & - & $Y_{1}$ \\
\hline 2 & - & - & + & $Y_{2}$ \\
\hline 3 & - & + & - & $Y_{3}$ \\
\hline 4 & - & + & + & $Y_{4}$ \\
\hline 5 & + & - & - & $Y_{5}$ \\
\hline 6 & + & - & + & $Y_{6}$ \\
\hline 7 & + & + & - & $Y_{7}$ \\
\hline 8 & + & + & + & $Y_{8}$ \\
\hline
\end{tabular}
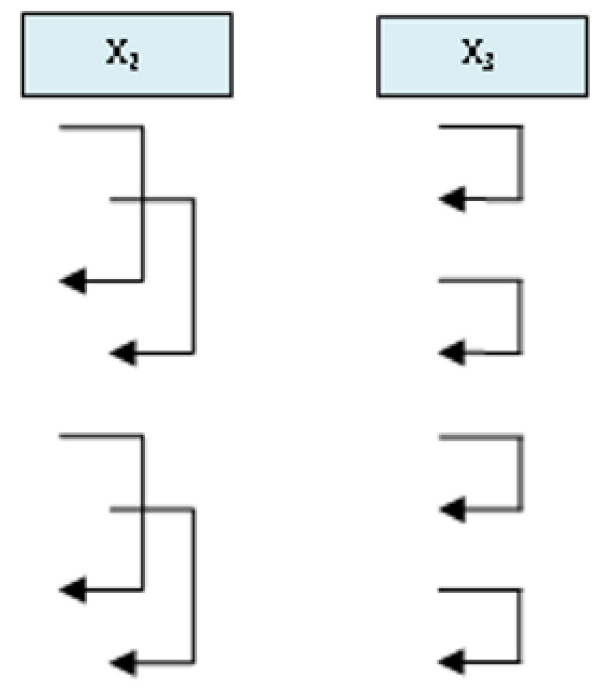

Figure 2. The assessment of the effect of each parameter, $X_{1}, X_{2}$, and $X_{3}$, for the designed threeparameter two-level experiment.

Thus, the actual effect of parameters $X_{1}, X_{2}$, and $X_{3}$ was calculated using Equations (A2)-(A4).

The most important advantage of factorial design of an experiment is that it allows one to evaluate the interactions between parameters. Interaction means that the influence of one parameter depends on the value (level) of one or more other parameters. The simplest type of interactions are two-factor $\left(X_{1} X_{2}, X_{1} X_{3}\right.$ and $\left.X_{2} X_{3}\right)$; the interaction of higher-order factors here is $X_{1} X_{2} X_{3}$.

\section{Results}

The results of the direct shear test for each paired experimental sample set are presented in Table 2, where samples 2, 4, 6, 8 were those subjected to 10 freeze-thaw cycles, and samples 1, 3, 5, 7 were their analogs in the original state of density and moisture content, as presented in Table 3.

The actual interaction effect between the factors can be calculated by multiplying the interaction factors and the subsequent sum of the products of the obtained value by the result of the experiment in Table 4. For example, the actual effect of interaction of factors 
$X_{1} X_{2}$ is calculated with Equations (A5)-(A7). The actual effect of interaction of factors $X_{1} X_{3}$ and $X_{2} X_{3}$, as well as $X_{1} X_{2} X_{3}$, was calculated similarly.

Table 3. Calculation of the actual effect of factors and their interactions.

\begin{tabular}{|c|c|c|c|c|c|c|c|c|c|c|c|c|}
\hline \multirow{2}{*}{ No. } & \multicolumn{3}{|c|}{ Factor } & \multicolumn{3}{|c|}{ Parameters (Coded) } & \multicolumn{4}{|c|}{ Additional Calculations } & \multicolumn{2}{|c|}{ Result } \\
\hline & $\begin{array}{c}\text { e, } \\
\text { u.f. }\end{array}$ & $\mathrm{W}, \%$ & Nc, pcs & $X_{1}$ & $X_{2}$ & $X_{3}$ & $X_{1} X_{2}$ & $X_{1} X_{3}$ & $X_{2} X_{3}$ & $X_{1} X_{2} X_{3}$ & $\varphi,^{\circ}$ & $\begin{array}{c}\mathrm{C}_{\prime} \\
\mathrm{kPa}\end{array}$ \\
\hline 1 & 0.55 & 22.6 & 0 & - & - & - & 1 & 1 & 1 & -1 & 8 & 36 \\
\hline 2 & 0.55 & 22.6 & 10 & - & - & + & 1 & -1 & -1 & 1 & 12 & 24 \\
\hline 3 & 0.55 & 16.5 & 0 & - & + & - & -1 & 1 & -1 & 1 & 12 & 39 \\
\hline 4 & 0.55 & 16.5 & 10 & - & + & + & -1 & -1 & 1 & -1 & 13 & 28 \\
\hline 5 & 0.75 & 22.6 & 0 & + & - & - & -1 & -1 & 1 & 1 & 12 & 13 \\
\hline 6 & 0.75 & 22.6 & 10 & + & - & + & -1 & 1 & -1 & -1 & 18 & 3 \\
\hline 7 & 0.75 & 16.5 & 0 & + & + & - & 1 & -1 & -1 & -1 & 12 & 26 \\
\hline 8 & 0.75 & 16.5 & 10 & + & + & + & 1 & 1 & 1 & 1 & 13 & 25 \\
\hline \multicolumn{13}{|c|}{ Actual effect } \\
\hline$\Delta \varphi,{ }^{\circ}$ & & & & 2.50 & 0.00 & 3.00 & -2.50 & 0.50 & -2.00 & -0.50 & & \\
\hline$\Delta \mathrm{c}, \mathrm{kPa}$ & & & & -15.00 & 10.50 & -8.50 & 7.00 & 3.00 & 2.50 & 2.00 & & \\
\hline
\end{tabular}

Table 4. Average effect of factors $X_{1}, X_{2}$, and $X_{3}$ on the strength characteristics of soils.

\begin{tabular}{|c|c|c|c|c|c|c|}
\hline \multicolumn{7}{|c|}{ Average Effect of Factors on $\frac{\varphi,{ }^{\circ}}{c, k P a}$} \\
\hline \multicolumn{2}{|c|}{ Factor (Coded) } & \multirow{2}{*}{$\begin{array}{c}\text { Level (-) } \\
0.55\end{array}$} & \multirow{2}{*}{$\begin{array}{c}Y(-)_{a v g} \\
\frac{11.25}{31.75}\end{array}$} & \multirow{2}{*}{$\begin{array}{c}\text { Level (+) } \\
0.75\end{array}$} & \multirow{2}{*}{$\frac{Y(+)_{a v g}}{\frac{13.75}{16.75}}$} & \multirow{2}{*}{ 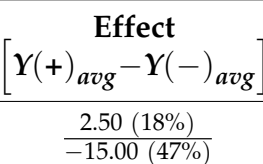 } \\
\hline$X_{1}$ & E, u.f. & & & & & \\
\hline$X_{2}$ & $\mathrm{~W}, \%$ & 22.6 & $\frac{12.50}{19.00}$ & 16.5 & $\frac{12.50}{29.50}$ & $\frac{0.00(0 \%)}{10.50(36 \%)}$ \\
\hline$X_{3}$ & $\mathrm{Nc}$ & 0 & $\frac{11.00}{28.50}$ & 10 & $\frac{14.00}{20.00}$ & $\frac{3.00(21 \%)}{-8.50(30 \%)}$ \\
\hline
\end{tabular}

The results of statistical analysis revealed that the void ratio of soil had the greatest effect on the change in the angle of internal friction: with the void ratio $e=0.75$, the angle of internal friction was, on average, $2.50^{\circ}(18 \%)$ greater with $\mathrm{e}=0.55$. The soil moisture content and the number of freezing-thawing cycles had a lesser effect, and the latter factor led to an increase in the angle of internal friction by an average of $3.00^{\circ}(21 \%)$.

Void ratio and initial moisture content had the greatest effect on the change in cohesion; both factors had a negative effect on the characteristic (15.00 and $10.50 \mathrm{kPa}$, which corresponds to $47 \%$ and $36 \%$ ). With a lower number of freeze-thaw cycles, the soil had a higher cohesion by $8.50 \mathrm{kPa}$ on average, which corresponds to $30 \%$. (Table 4 ).

Statistical analysis of the experimental data results (Figure 3 ) showed that the void ratio and the soil moisture content both had a significant effect on the strength characteristics of the soil. The angle of internal friction of soil with a void ratio of 0.55 decreased on average by $2.5^{\circ}(20 \%)$ if the moisture content increased from $16.5 \%$ to $22.6 \%$. However, the angle of internal friction of soil with a void ratio of 0.75 increased by $2.50^{\circ}(17 \%)$ if the moisture content increased within the above limits. It is important to note that with an initial soil moisture content of $22.6 \%$, the angle of internal friction of soil with a void ratio of 0.55 was $5.00^{\circ}(33 \%)$ lower (Figure 3).

The cohesion of soil with a void ratio of 0.55 decreased by $3.50 \mathrm{kPa}(10 \%)$ if the moisture content increased within the above range, and that of soil with a void ratio $\mathrm{e}=0.75$ decreased by $17.50 \mathrm{kPa}(69 \%)$. With an initial soil moisture content of $16.5 \%$, the cohesion of soil with a void ratio of 0.55 was $8.00 \mathrm{kPa}(24 \%)$ higher, and with an initial soil moisture content of $22.6 \%$ it was higher by $22.00 \mathrm{kPa}$, i.e., by $73 \%$ (Figure 3 ). 

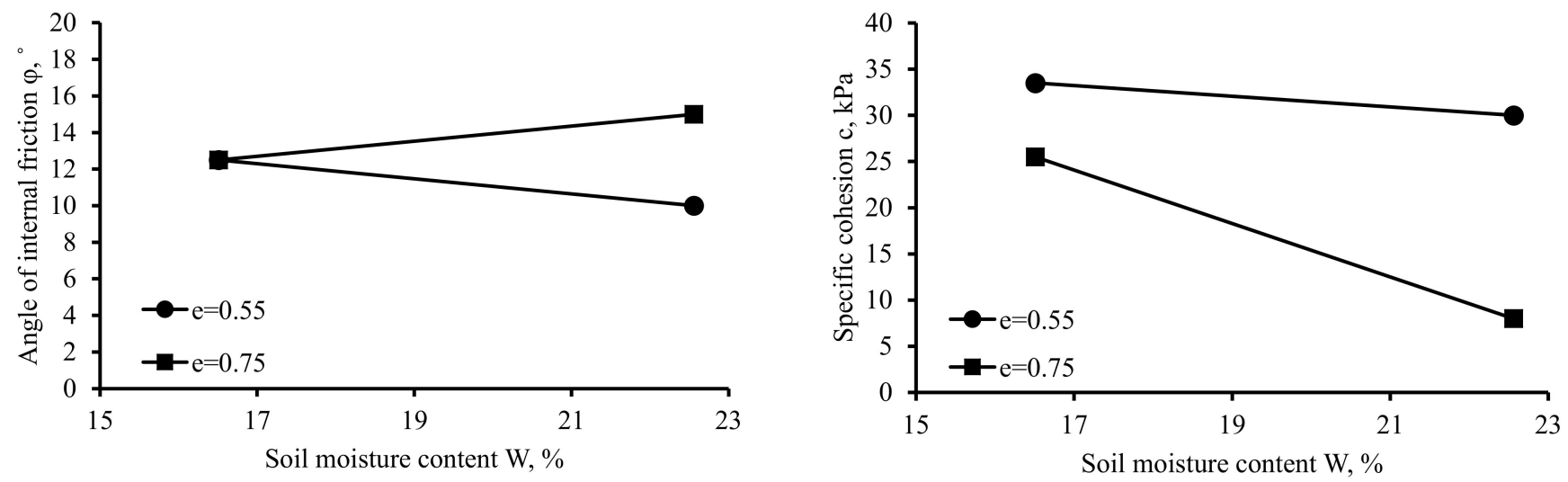

Figure 3. Effect of the interaction of factors $X_{1} X_{2}$ on the strength characteristics of soil.

The combination of the void ratio and the number of freezing-thawing cycles also had a significant effect on the strength characteristics of the soil. (Figure 4).
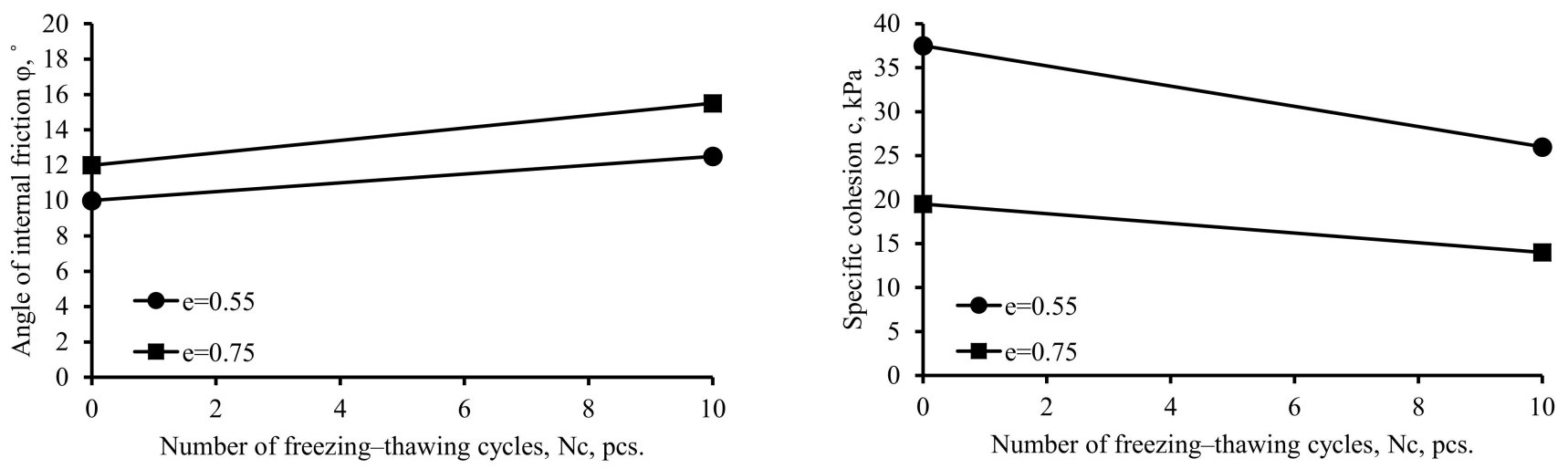

Figure 4. Effect of the interaction of factors $X_{1} X_{3}$ on the strength characteristics of soil.

The angle of internal friction of soil with a void ratio of 0.55 increased by $2.5^{\circ}(20 \%)$ during freezing-thawing cycles. The angle of internal friction of soil with a void ratio of 0.75 increased by $3.50^{\circ}(23 \%)$ during freezing-thawing cycles. It should be noted that the angle of internal friction of soil with a void ratio of 0.55 was $2.0^{\circ}(17 \%)$ lower, without freezing-thawing. The angle of internal friction of soil with a void ratio of 0.55 was $3^{\circ}(19 \%)$ lower during freezing-thawing.

Cohesion of the soil during freezing-thawing cycles dropped drastically by $11.50 \mathrm{kPa}$ $(31 \%)$ and $5.50 \mathrm{kPa}(28 \%)$ for soil with void ratios of 0.55 and 0.75 , respectively. The cohesion of soil with a void ratio of 0.55 was $18.00 \mathrm{kPa}(48 \%)$ higher without the effect of freezing-thawing. The cohesion of soil with a void ratio of 0.55 was $12.00 \mathrm{kPa}(46 \%)$ higher during freezing-thawing cycles. Cohesion was revealed to be the most sensitive parameter influenced by the freeze-thaw cycles.

In addition, the average effect of both the initial soil moisture content and the number of freezing-thawing cycles on the cohesion and the angle of internal friction was considered. The results are shown in Figure 5.

The angle of internal friction of soil with an initial moisture content of $16.5 \%$ did not change during freezing-thawing. However, the angle of internal friction of soil with an initial moisture content of $22.6 \%$ increased by $5^{\circ}(33 \%)$ during freezing-thawing. It should be noted that the angle of internal friction of soil with an initial moisture content of $22.6 \%$ was $2.50^{\circ}(20 \%)$ lower without freezing-thawing. The angle of internal friction of soil which underwent 10 freezing-thawing cycles was $2.00^{\circ}(13 \%)$ higher for the soil with the initial moisture content of $22.6 \%$. 
The cohesion of soil with initial moisture contents of $16.5 \%$ and $22.6 \%$ decreased by $11.00 \mathrm{kPa}(45 \%)$ and $6.00 \mathrm{kPa}(18 \%)$, respectively, during freezing-thawing. It is important to note that the cohesion of soil without freezing-thawing was lower by 8.00 (25\%) for the soil with an initial moisture content of $22.6 \%$.
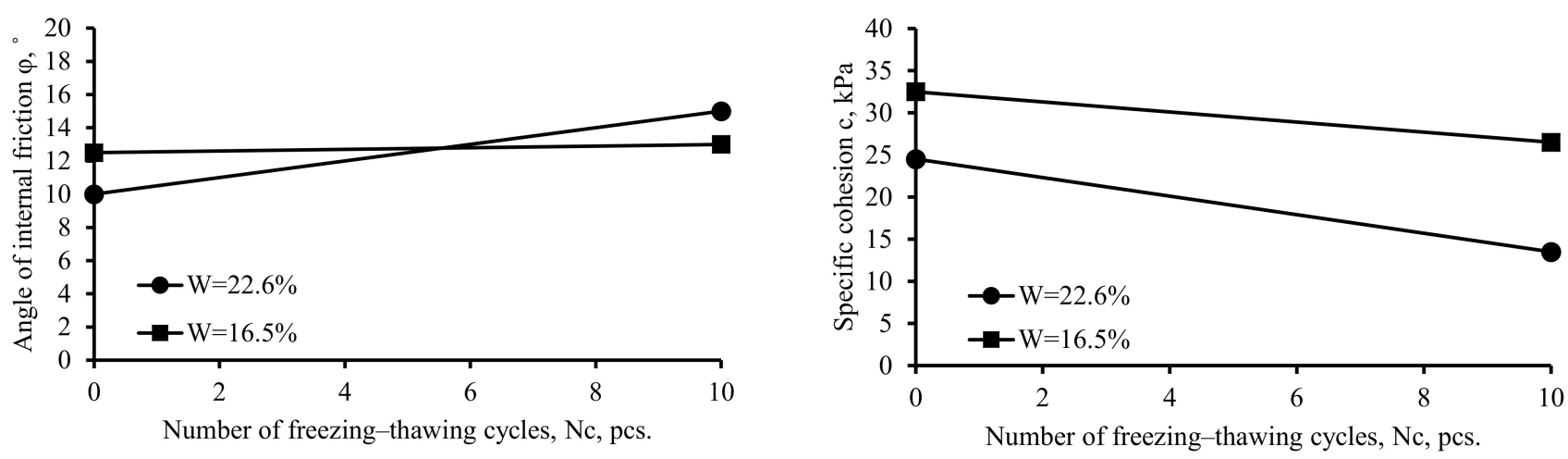

Figure 5. Effect of the interaction of factors $X_{2} X_{3}$ on the strength characteristics of soil.

In a three-dimensional way, the described dependence can be represented as shown in Figure 6. An intermediate value of the soil strength characteristic can be found by using the presented graphical dependence. Figure 6a shows the intermediate value of the internal friction angle for soil with a void ratio equal to 0.75 , with 10 freezing-thawing cycles, and with an initial moisture content of $19.0 \%$. The resulting value is $15.1^{\circ}$.

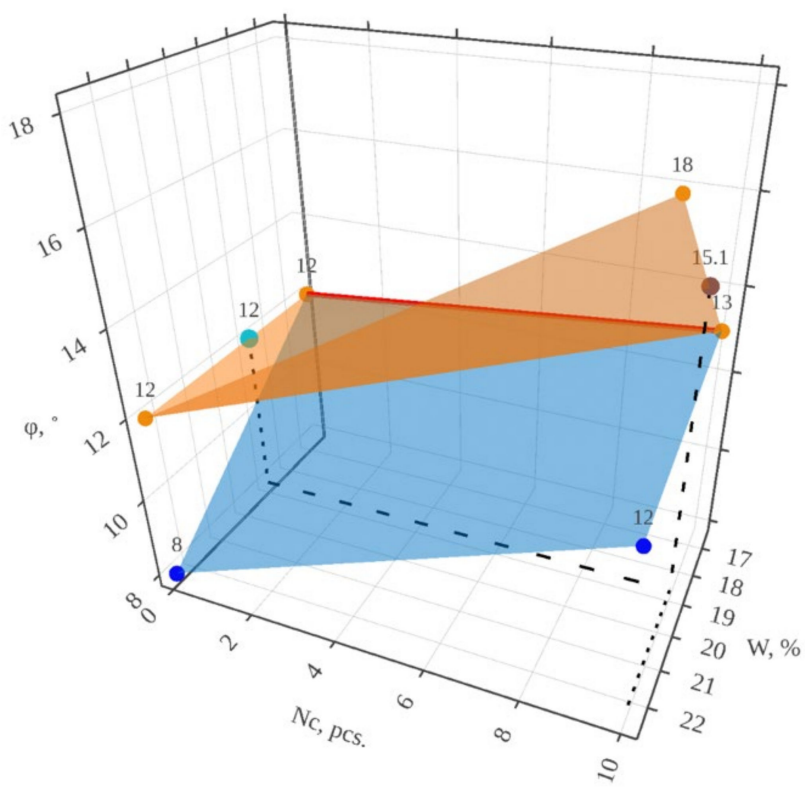

(a)

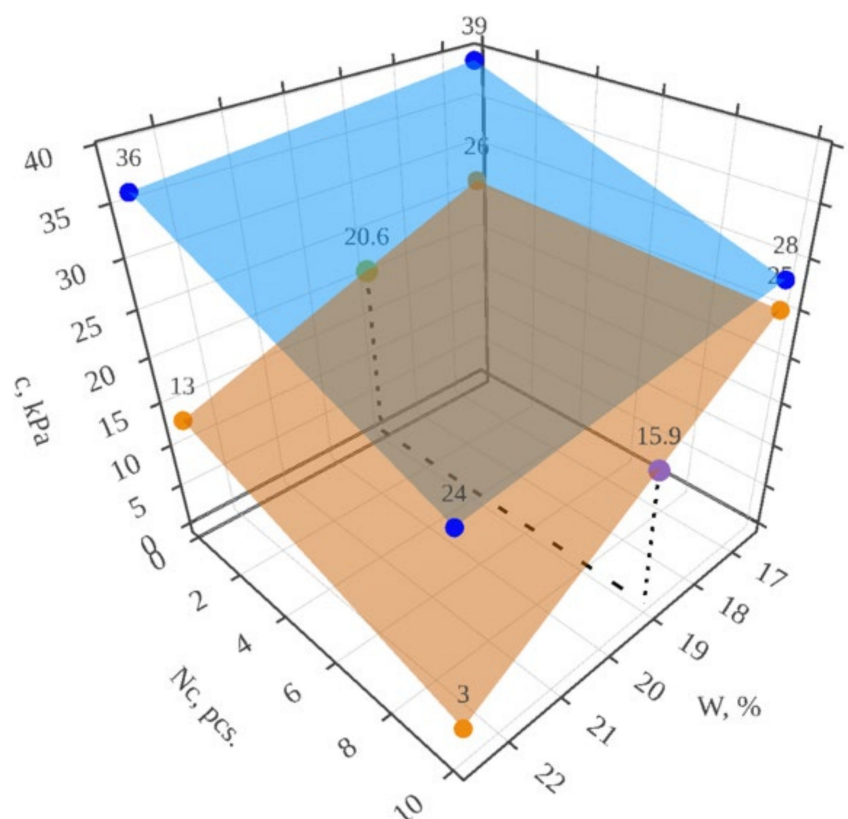

(b)

Figure 6. Dependence of the strength characteristics of soil on the void ratio, initial moisture content, and the number of freezing-thawing cycles, shown in a three-dimensional manner: (a)—for the angle of internal friction; (b) - for cohesion.

In addition, Figure $6 \mathrm{a}$ indicates the uncertainty of the behavior of the angle of internal friction depending on the void ratio. Thus, at a moisture content of $22.6 \%$, the angle of internal friction is lower for soil with a void ratio of 0.55 . However, if the moisture content decreases, the nature of the change in characteristics, depending on the void ratio, changes in the opposite direction, forming a line of intersection of two planes. At the same time, 
the change in cohesion depending on the void ratio is unambiguous, which is shown in Figure $6 \mathrm{~b}$. Figure $6 \mathrm{a}$ shows the intermediate value of the cohesion for the soil with a void ratio equal to 0.75 , with 10 freezing-thawing cycles and with an initial moisture content of $19.0 \%$. The resulting value is $15.9 \mathrm{kPa}$.

\section{Discussion}

Based on the results of laboratory research, a dependence was derived that allows to determine the angle of internal friction or cohesion on the given data of void ratio, initial soil moisture, and number of freeze-thaw cycles. A program based on the least-squares method has the following form:

$$
y=e^{a_{0}+a_{1} X_{1}+a_{2} X_{2}+a_{3} X_{3}+b_{1} X_{1}^{2}+b_{2} X_{2}^{2}+b_{3} X_{3}^{2}+c_{1} X_{1} X_{2}+c_{2} X_{1} X_{3}+c_{3} X_{2} X_{3}}
$$

where $\boldsymbol{a}_{\boldsymbol{i}}, \boldsymbol{b}_{\boldsymbol{i}}$, and $\boldsymbol{c}_{\boldsymbol{i}}$ is the approximation coefficient;

$X_{\mathbf{i}}$ is the value of the factor under study.

The developed program for calculating the dependence of the desired parameter on the given values allows us to process the results of a three-factor experiment. The general view of the program is presented in Figure 7. The figure shows the results of calculating the approximation coefficients for the angle of internal friction.

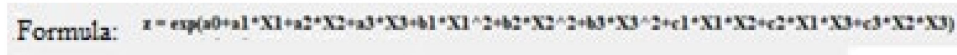

Approximation coefficients:

$a(0)=5.093 ; a(1)=-3.328 ; a(2)=-0.162 ; a(3)=1.797 ; a(4)=-1.625 ;$

$a(5)=-0.002 ; a(6)=-0.155 ; a(7)=0.332 ; a(3)=0 ; a(9)=0.005$

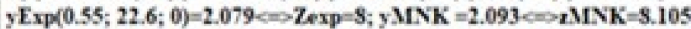

y $\operatorname{Exp}(0.55 ; 22.6 ; 10)=2.485 \Leftrightarrow Z e x p=12 ; y \mathrm{MNK}=2.436 \Leftrightarrow 2 \mathrm{MNK}=12.012$

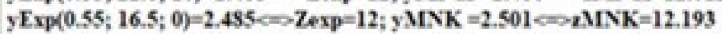

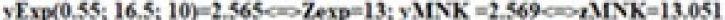

vip $(0.75 ; 22.6 ; 0)=2.4550-2 e x p=12 ; y$ MNK $=2.5060 x$ MNK $=12.252$

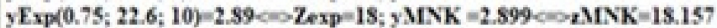

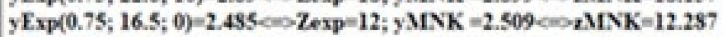

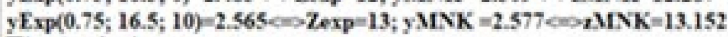

Theoretical error: $\min \%=0 ;$ max $\%=1$

Root-mean-1quare error $=0.0143$

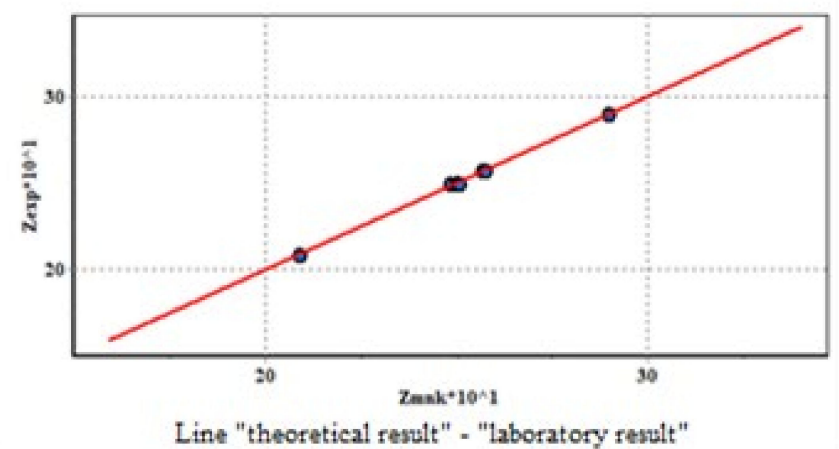

Line "theoretical result" - "laboratory result"

Figure 7. General view of the program.

For the angle of internal Friction (2) and Cohesion (3), the mathematical dependence can be represented as follows:

$$
y=e^{5.093-3.328 \cdot X_{1}-0.162 \cdot X_{2}+1.797 \cdot X_{3}-1.628 \cdot X_{1}{ }^{2}-0.002 \cdot X_{2}{ }^{2}-0.188 \cdot X_{3}{ }^{2}+0.332 \cdot X_{1} X_{2}+0.005 \cdot X_{2} X_{3}}
$$

$$
y=e^{2.696+10.277 \cdot X_{1}-0.129 \cdot X_{2}-4.049 \cdot X_{3}+5.206 \cdot X_{1}{ }^{2}+0.019 \cdot X_{2}{ }^{2}+0.436 \cdot X_{3}{ }^{2}-1.057 \cdot X_{1} X_{2}-0.192 \cdot X_{1} X_{3}-0.012 \cdot X_{2} X_{3}}
$$

where $X_{i}$ is the value of the factor under study $\left(X_{1}\right.$ is the soil void ratio; $X_{2}$ is the initial soil moisture content; $X_{3}$ is the number of freezing-thawing cycles).

Figure 8 shows a graph of the correspondence of the results of laboratory and theoretical values of strength characteristics. The axis of the abscissa indicates the value of the characteristic calculated according to Equations (2) and (3). The axis of the ordinate represents the value of the characteristic obtained as a result of laboratory studies. With perfect correspondence, the points should be located on the line $Y=X$. Figure 8 shows that the closest correspondence is observed for the angle of internal friction. 


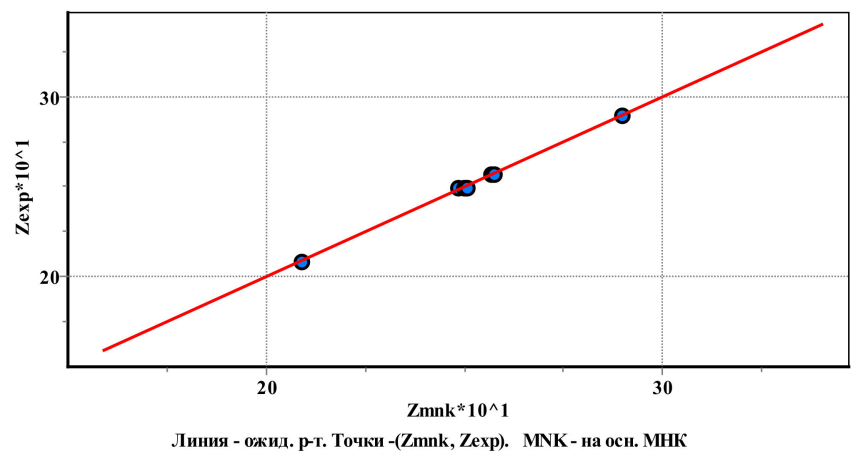

(a)

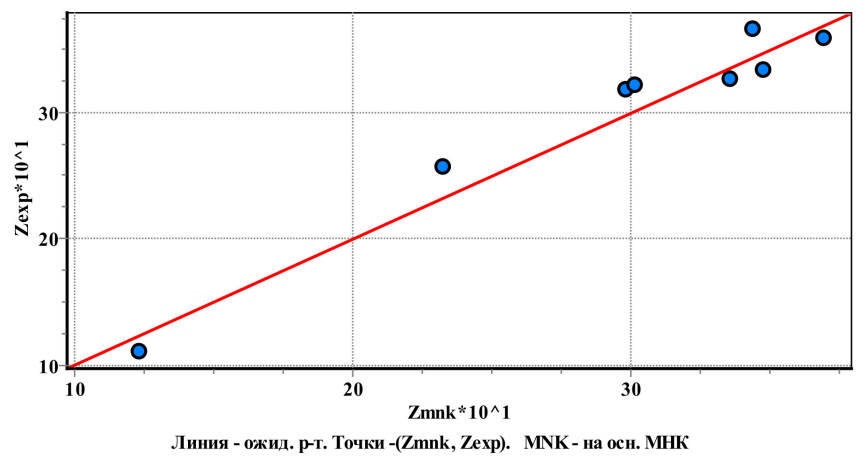

(b)

Figure 8. The correspondence of the results of laboratory and theoretical values of strength characteristics: (a) —angle of internal friction; (b) — cohesion.

Thus, by setting the values of void ratio, initial soil moisture, and number of freezethaw cycles, it becomes possible to calculate the angle of internal friction and/or cohesion for each type of soil. However, the presented dependencies work correctly only near the points of interest. Therefore, additional tests are required inside the cube (Figure 1) to clarify these mathematical dependences.

\section{Example Calculation of Engineering Characteristics of Soil Bases by the Proposed Analytical Method}

In order to verify the proposed method, in this subsection, the following example was considered to determine the angle of internal friction and cohesion and compare it with the calculated values; the bearing capacity of the soil was determined according to the standard [18] of the Russian Federation. According to the design standards, when calculating the strains of the soil base of building foundations, the average pressure under the foundation footing should not exceed the design soil resistance $\mathrm{R}$, which is calculated by Equation (4) in accordance with SP 22.13330.2016 "Soil bases of buildings and structures" [18] which allows the determination of the linear load in the soil base,

$$
R=\frac{\gamma_{c 1} \gamma_{c 2}}{k}\left[M_{\gamma} k_{z} b \gamma_{I I}+M_{q} d_{l} \gamma_{I I}^{\prime}+\left(M_{q}-1\right) d_{b} \gamma_{I I}^{\prime}+M_{c} c_{I I}\right]
$$

As an example, below is the calculation of the general case of strength characteristics with the following initial data:

1. The foundation footing width $\boldsymbol{b}=\mathbf{1 0} \mathrm{m}$, therefore $k_{z}=\frac{z_{0}}{b}+\mathbf{0 . 2}=\mathbf{1}$.

2. The foundation depth $\boldsymbol{d}_{\boldsymbol{l}}=\mathbf{5} \mathrm{m}$.

3. The basement depth $\boldsymbol{d}_{\boldsymbol{b}}$ is assumed equal to $2 \mathrm{~m}$ in accordance with SP 22.13330.2016 [18].

4. The building has a rigid structure; the ratio of the length of the structure to its height $\mathrm{L} / \mathrm{H}$ is less than 1.5 .

5. The strength characteristics of the soil are determined by direct tests, therefore $\boldsymbol{k}=\mathbf{1}$.

6. Depending on the calculated angle of internal friction, coefficients $\boldsymbol{M}_{\gamma}, \boldsymbol{M}_{\boldsymbol{q}}$, and $\boldsymbol{M}_{\boldsymbol{c}}$ are taken according to SP 22.13330.2016 [18].

7. The soil base is homogeneous, i.e., $\gamma_{I I}=\gamma_{I I}^{\prime}$.

8. Coefficients $\gamma_{c 1}$ and $\gamma_{c 2}$ are accepted according to SP 22.13330.2016 [18], depending on the type of soil and its initial moisture content.

Table 5 is a summary of the calculation results of determining the engineering characteristics by the analytical method. Here, $\varphi_{n}$ and $c_{n}$ are the normative values of angle of internal friction and cohesion determined in the laboratory, whereas $\varphi_{I I}$ and $c_{I I}$ are design values. 
Table 5. Calculation of the engineering characteristics by the analytical method.

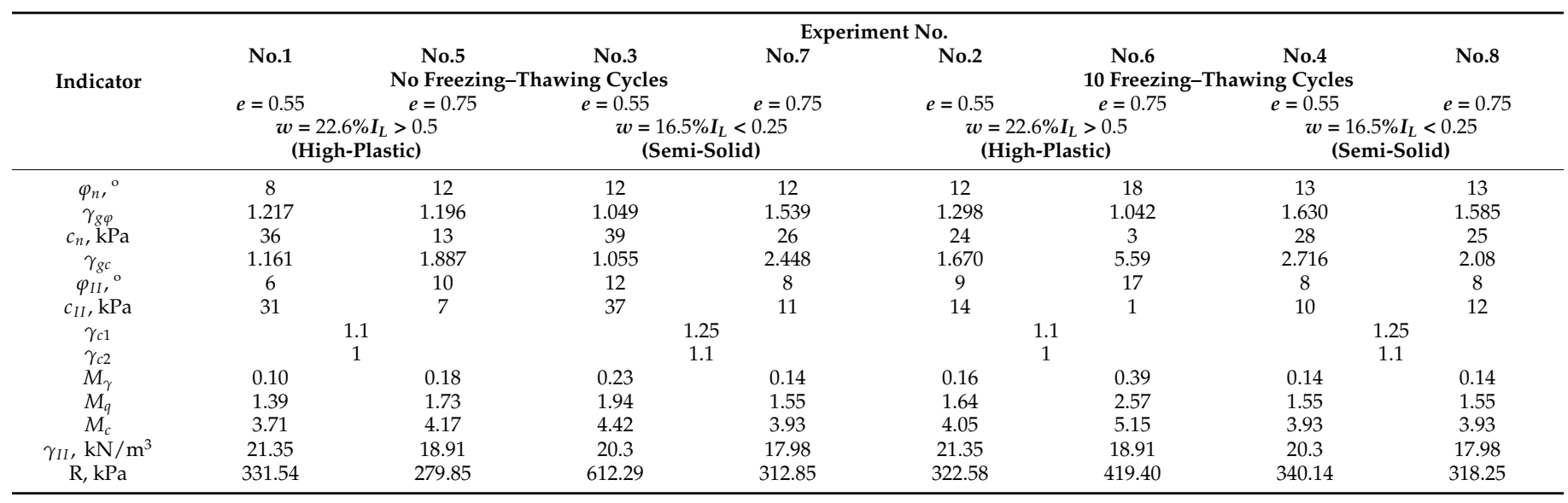

As can be seen from the results in Table 5, Figure 9, the freezing-thawing cycles significantly reduced the bearing capacity of the soil base. The largest decrease in design soil resistance $\mathrm{R}$ was by up to $44 \%$ after 10 freezing-thawing cycles, which was observed for the soils with $\boldsymbol{e}=0.55$ and $\boldsymbol{w}=\mathbf{1 6 . 5 \%}$. For the soils with initial characteristics $\boldsymbol{e}=\mathbf{0 . 7 5}$ and $\boldsymbol{w}=\mathbf{2 2 . 6 \%}$, the design soil resistance increased by $33 \%$ after freezing-thawing cycles, which is obviously associated with additional soil compaction.

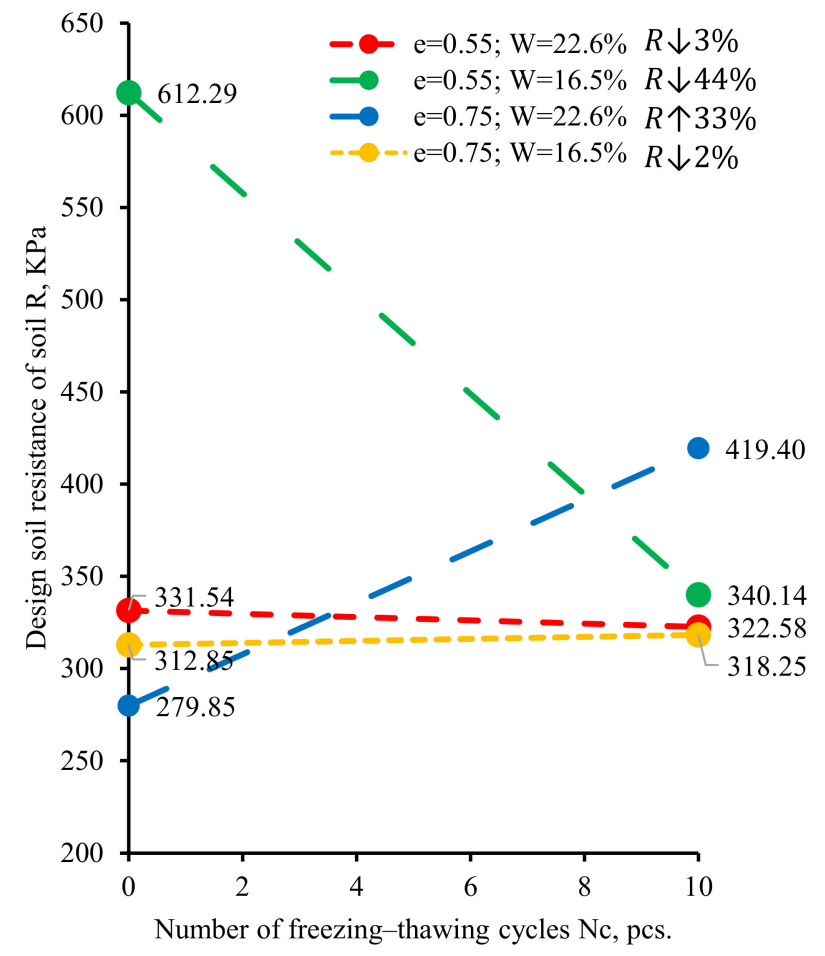

Figure 9. Dependence of design soil resistence from the number of freezing-thawing cycles.

Thus, in the case of an unfavorable combination of the type of soil, its condition, and environmental factors, if a decrease in the design soil resistance is not taken into account, additional settlement of the upper soil base layer may also be not accounted for. This is due to its non-linear operation at an average pressure exceeding R. In some cases, this can lead to soil uplift from under the building foundation and its significant subsidence. 


\section{Conclusion}

In this work, a three-parameter paired experiment was conducted in order to analyze the influence of void ratio, initial moisture content, and the number of freezing-thawing cycles on the engineering characteristics of soil, such as angle of internal friction and cohesion. According to the results of the study, the following outcomes were highlighted:

1. The factors under study greatly affect the cohesion of the soil and, together, can decrease it by up to three times. The angle of internal friction has an indefinite behavior when the parameters under study change, which is confirmed by the literature review. Consequently, taking into account the reduction in cohesion is mandatory in engineering practice, whereas taking into account the change in the angle of internal friction is only recommended.

2. A program based on the least-squares method was used to calculate the approximation coefficients of the dependence describing the changes in strength characteristics from the abovementioned parameters under study based on experiment results. Thus, by setting the values of void ratio, initial soil moisture, and number of freeze-thaw cycles, it became possible to calculate the angle of internal friction and/or cohesion for each type of soil.

3. Freezing-thawing cycles significantly decreased the bearing capacity of the soils: by $44 \%$ after 10 freezing-thawing cycles for soil with $\mathrm{e}=0.55$ and $\mathrm{w}=16.5 \%$. However, in the case of $\mathrm{e}=0.75$ and $\mathrm{w}=22.6 \%$, the bearing capacity of the soils increased by $33 \%$, exceeding all expectations. Such changes in strength characteristics must be taken into account when designing structures, as they can lead to additional settlement or even subsidence of the foundations during the freezing-thawing cycles while exploiting.

Author Contributions: Conceptualization, Y.P. and A.Z.; Data curation, A.Z. and U.Z.S.; Formal analysis, E.B. and A.G.; Funding acquisition, T.M. and U.Z.S.; Investigation, E.B.; Methodology, E.B., A.G. and A.S.; Project administration, T.M.; Resources, U.Z.S.; Software, A.G. and T.M.; Supervision, Y.P. and A.Z.; Validation, T.M.; Visualization, E.B. and A.S.; Writing-original draft, E.B. and Y.P.; Writing-review \& editing, A.S. and U.Z.S. All authors have read and agreed to the published version of the manuscript.

Funding: This research received no external funding.

Institutional Review Board Statement: Not applicable.

Informed Consent Statement: Not applicable.

Data Availability Statement: Data available on request from the corresponding author.

Conflicts of Interest: The authors declare no conflict of interest.

\section{Appendix A}

$$
S=S_{\text {comp }}+S_{\text {elast }}+S_{\text {destr }}+S_{\text {heaver }}
$$

where $S_{\text {comp }}$ is the calculated value of the final settlement, according to regulations, which is a consequence of repacking of particles under a load, leading to soil compaction, within the compressible thickness.

$S_{\text {elast }}$ is settlement associated with the unloading of the excavation and the subsequent construction of the foundation and backfilling with soil.

$S_{\text {destr }}$ is settlement associated with destructuring of soil, for example, under the influence of heavy machinery, frost exposure, water saturation, unfavorable weather conditions, etc.

$S_{\text {heave }}$ is heave settlement associated with the accumulation of shear strains in the soil leading to the squeezing out of the soil from under the base of the foundation.

Effect of parameter $X_{1}=\frac{\left[\left(Y_{5}-Y_{1}\right)+\left(Y_{6}-Y_{2}\right)+\left(Y_{7}-Y_{3}\right)+\left(Y_{8}-Y_{4}\right)\right]}{4}=\frac{Y_{5}+Y_{6}+Y_{7}+Y_{8}}{4}-\frac{Y_{1}+Y_{2}+Y_{2}+Y_{4}}{4}$ 


$$
\begin{array}{r}
\text { Effect of parameter } X_{2}=\frac{\left[\left(Y_{3}-Y_{1}\right)+\left(Y_{4}-Y_{2}\right)+\left(Y_{7}-Y_{5}\right)+\left(Y_{8}-Y_{6}\right)\right]}{4}=\frac{Y_{3}+Y_{4}+Y_{7}+Y_{8}}{4}-\frac{Y_{1}+Y_{2}+Y_{5}+Y_{6}}{4} \\
\text { Effect of parameter } X_{3}=\frac{\left[\left(Y_{2}-Y_{1}\right)+\left(Y_{4}-Y_{3}\right)+\left(Y_{6}-Y_{5}\right)+\left(Y_{8}-Y_{7}\right)\right]}{4}=\frac{Y_{2}+Y_{4}+Y_{6}+Y_{8}}{4}-\frac{Y_{1}+Y_{3}+Y_{5}+Y_{7}}{4} \\
\text { Effect of parameter } X_{1} X_{2}=\frac{+Y_{1}+Y_{2}-Y_{3}-Y_{4}-Y_{5}-Y_{6}+Y_{7}+Y_{8}}{4} \\
\text { Effect of parameter } X_{1} X_{2}\left(c_{,} \mathrm{kPa}\right)=\frac{+36+24-39-28-13-3+26+25}{4}=7.00 \\
\text { Effect of parameter } X_{1} X_{2}\left(\varphi,{ }^{\circ}\right)=\frac{+8+12-12-13-12-18+12+13}{4}=-2.5
\end{array}
$$

\section{References}

1. Wang, T.; Luo, S.; Liu, X. Testing Study of Freezing-Thawing Strength of Unsaturated Undisturbed Loess Considering Influence of Moisture Content. Rock Soil Mech. 2010, 31, 2378-2382.

2. Sarsembayeva, A.; Zhussupbekov, A. Experimental study of deicing chemical redistribution and moisture mass transfer in highway subsoils during the unidirectional freezing. Transp. Geotech. 2021, 26, 100426. [CrossRef]

3. Qi, J.; Ma, W.; Song, C. Influence of Freeze-Thaw on Engineering Properties of a Silty Soil. Cold Reg. Sci. Technol. 2008, 53, 397-404. [CrossRef]

4. Yarbaşı, N.; Kalkan, E.; Akbulut, S. Modification of the geotechnical properties, as influenced by freeze-thaw, of granular soils with waste additives. Cold Reg. Sci. Technol. 2007, 48, 44-54. [CrossRef]

5. Kalkan, E. Effects of silica fume on the geotechnical properties of fine-grained soils exposed to freeze and thaw. Cold Reg. Sci. Technol. 2009, 58, 130-135. [CrossRef]

6. Ghazavi, M.; Roustaie, M. The Influence of Freeze-Thaw Cycles on the Unconfined Compressive Strength of Fiber-Reinforced Clay. Cold Reg. Sci. Technol. 2010, 61, 125-131. [CrossRef]

7. Goldstein, M.N. Deformation of the Subgrade and Foundations of Structures during Freezing and Thawing; Transzheldorizdat: Moscow, Russia, 1948; 212p.

8. Pchelintsev, A.M. Structure and Physical and Mechanical Properties of Frozen Soils; Publishing House "Nauka": Moscow, Russia, 1964; 260p.

9. Tsytovich, N.A. Mechanics of Frozen Soils; Study Guide; Vysshaya Shkola: Moscow, Russia, 1973; 448p.

10. Tsytovich, N.A. Foundations on Frozen Ground; USSR Academy of Sciences Publishing House: Moscow, Russia, 1958; 168p.

11. Shusherina, E.P.; Rachevsky, B.S.; Otroshchenko, O.P. Study of temperature deformations of frozen rocks. In Permafrost Research; MSU Publishing House: Moscow, Russia, 1970; pp. 273-283.

12. Medvedev, S.N. Technology of Construction of Foundations of Buildings on Seasonally Freezing Soils: Author's Abstract of the Dissertation for the Degree of Candidate of Technical Sciences: 05.23.08/Sergey Nazarovich Medvedev; MGSU: Moscow, Russia, 2007; 22p.

13. Kiselev, M.F. Prevention of Soil Deformation from Frost Heaving; Leningrad: Stroyizdat, Russia, 1985; 131p.

14. Ling, X.; Zhang, F.; Zhu, Z. Field Experiment of Subgrade Vibration Induced by Passing Train in a Seasonally Frozen Region of Daqing. Earthq. Eng. Eng. Vib. 2009, 8, 149-157. [CrossRef]

15. Li, Q.; Ling, X.; Sheng, D. Elasto-Plastic Behaviour of Frozen Soil Subjected to Long-Term Low-Level Repeated Loading, Part I: Experimental Investigation. Cold Reg. Sci. Technol. 2016, 125, 138-151. [CrossRef]

16. Tebaldi, G.; Orazi, M.; Orazi, U.S. Effect of Freeze-Thaw Cycles on Mechanical Behavior of Lime-Stabilized Soil. J. Mater. Civ. Eng. 2016, 28, 06016002. [CrossRef]

17. Magushev, R.A.; Karlov, V.D.; Sakharov, I.I.; Osokin, A.I. Foundation Engineering: Textbook for Bachelors of Construction; ASV Publishing House: Moscow, Russia; SPbGASU: Saint Petersburg, Russia, 2011; 394p.

18. Code of Practice SP 22.13330.2016. Soil Bases of Buildings and Structures; Updated Edition of SNiP 2.02.01-83*(2014); Standartinform: Moscow, Russia, 2016; 227p.

19. Chang, D.; Liu, J.; Li, X.; Yu, Q. Experiment Study of Effects of Freezing-Thawing Cycles on Mechanical Properties of Qinghat-Tibet Silty Sand. Chin. J. Rock Mech. Eng. 2014, 33, 1496-1502.

20. Wang, D.Y.; Ma, W.; Chang, X.X.; Sun, Z.Z.; Feng, W.J.; Zhang, J.W. Physico-Mechanical Properties Changes of Qinghai-Tibet Clay due to Cyclic Freezing and Thawing. Chin. J. Rock Mech. Eng. 2005, 24, 4313-4319.

21. Wang, M.; Meng, S.; Sun, Y.; Fu, H. Shear strength of frozen clay under freezing-thawing cycles using triaxial tests. Earthq. Eng. Eng. Vib. 2018, 17, 761-769. [CrossRef]

22. Yu, J. Design of Low Temperature Triaxial Testing Machine and Experimental Study on Cyclic Freeze-Thaw on the Mechanical Properties of Silty Clay. Ph.D. Dissertation, Wuhan Insitute of Rock and Soil Mechanics, The Chinese Academy of Sciences, Wuhan, China, 2007.

23. Liu, J.; Chang, D.; Yu, Q. Influence of freeze-thaw cycles on mechanical properties of a silty sand. Eng. Geol. 2016, 210, 23-32. [CrossRef] 
24. Zhang, H.; Wang, T.; Luo, Y. Freezing-Thawing Strength of Unsaturated Undisturbed Loess. J. Northwest AF Univ. (Nat. Sci. Ed.) 2015, 43, 1-6.

25. Fang, L.; Qi, J.; Ma, W. Freeze-Thaw Induced Changes in Soil Structure and its Relationship with Variations in Strength. J. Glaciol. Geocryol. 2012, 34, 435-440.

26. Su, Q.; Tang, D.; Liu, S. Test on Physico-Mechanical Properties of Qinghai-Tibet Slope Clay under Freezing-Thawing Cycles. Chin. J. Rock Mech. Eng. 2008, 27, 2990-2994.

27. Dong, X.; Zhang, A.; Lian, J.; Guo, M. Laboratory Study on Shear Strength Deterioration of Loess with Long-Term FreezingThawing Cycles. J. Eng. Geol. 2010, 18, 887-893.

28. Wang, J. Research on the Mechanical Properties of Pavement Soil after Several Freeze Thaw Cycles in Seasonally Frozen Soil Region and Microscopic Mechanism Analysis. Ph.D. Dissertation, Jilin University, Changchun, China, 2012.

29. GOST 30416-2012. Soils. Laboratory Testing. General. Available online: https://docs.cntd.ru/document/1200096093 (accessed on 2 December 2021).

30. GOST 25100-2020. Soils. Classification. Available online: https://docs.cntd.ru/document/1200174302 (accessed on 2 December 2021).

31. GOST 12248-2010. Soils. Laboratory Methods for Determining the Strength and Strain Characteristics. Available online: https:/ / docs.cntd.ru/document/1200084869 (accessed on 2 December 2021).

32. Lawson, J.; Erjavec, J. Basic Experimental Strategies and Data Analysis for Science and Engineering; CRC Press, Taylor \& Francis Group: Boca Raton, USA, 2017; 445p. 